Helene Gomes

Sacco

Doutora em Arte

Doutora em Arte

(2014), Mestrado

em Artes

Visuais, enfase

Poéticas Visuais,

UFRGS(2009).

e Did́tica

Metodologia

de Ensino

Superior(2004)

Professor

colaboradora no

Mestrado em Artes

Visuais; Professora

do Centro de Artes

da UFPel em cursos

e Percepção

tridimensional

na modalidade

Licenciatura

Bacharelado

Design gráfico

digital na UFPEL

Pelotas-RS. Atua

como pesquisadora

nos seguintes

emas: Objeto,

desenho e palavra,

com enfase de

objetos cotidianos
invenções e (re)

fabricaçōes

inventários

ordinários e

relaçoes entre

\section{JAZIDA: entre livros, coleções, constelações e descobertas}

\section{JAZIDA: between books, collections, constellations and discoveries}

Resumo: $O$ texto apresenta e busca refletir sobre a proposição JAZIDA, desenvolvida pelo Gupo de Pesquisa Lugares-Livio. dimensôes poéticas e materiais (CNPq/ UFPEL). Tal proposição iniciou como estratégia de autodescoberta por via de um pequeno levantamento pessoal de bibliografia e seguilu com a criação de diálogos entre os participantes e da formação de constelações de referências, como um desenho invisível de conexão entre os membros do grupo. Ao analisar os resultados procura pensar no porquê escrever um livro, e no valor dado à leitura e escrita. Destaca a importância da formação de acervos de livros ao apresentar a experiência artística de colagem coletiva nos tapumes da obra de construção da Biblioteca de Ciências Humanas da UFPEL em 22 abril de 2015, véspera do dia Mundial do Livro.

Palavras-chave: Livros, bibliotecas, leitura, escrita, infraordinário

Abstract: IThis papel presents and reflects on the proposition JAZIDA (MINE), developed by the Research Group Book-Places: poetic dimensions and materials (CNPq/UFPEL). The proposition began as a strategy for self-discovery by means of a small personal survey of bibliographies, followed by the creation of dialogues between participants and the forming of constellations of references, a kind of invisible drawing of the connections between members of the group In analyzing the results, I consider reasons why I am writing a book and the value given to reading and writing I highlight the importance of book collections as I present the artistic experiences involving group collages that were made on the boards isoliting and exprounding the construction site of the Libray of Human Sciences of UFPEL and april 22, 2015, on the eve of World Book Day.

Keywords: Books, libraries, reading, writing, infra-ordinary

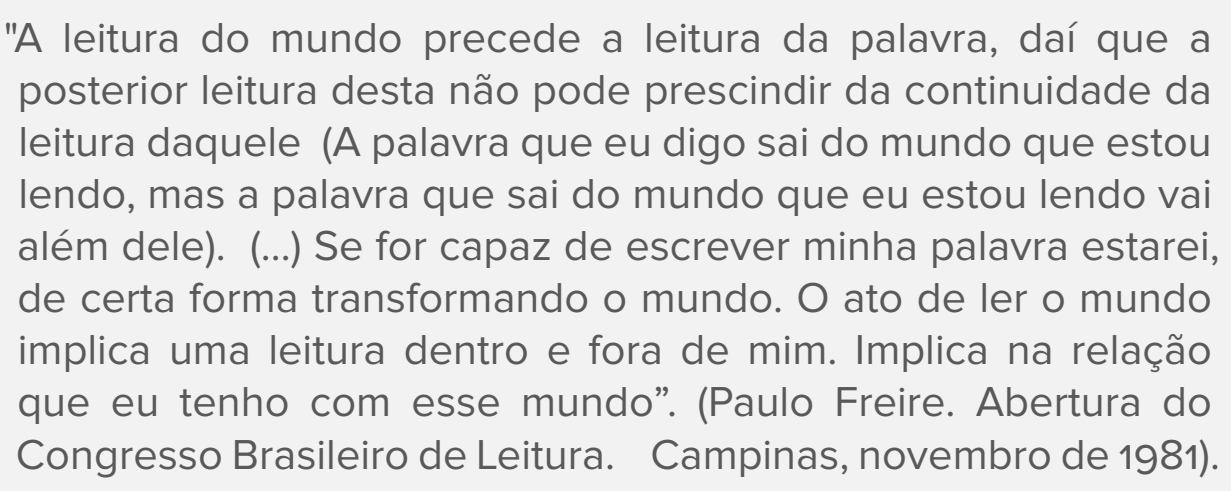

Num conto de Julio Cortázar chamado Fim do mundo do fim (2013), o mundo é invadido e remodelado por uma produção sem fim de livros, causando a explosão de bibliotecas e a tomada de campos, mares e oceanos pelo o excesso de livros que surgem sem cessar das mãos dos escribas. Nessa distopia, o número de leitores é muito inferior ao número de "escribas" e convida para uma reflexão fundamental a todo pesquisador e artista do universo dos livros. Por que escrever um livro?

Comecei assim o encontro do Grupo de Pesquisa Lugares-livro: dimensões poéticas e materiais, no ano de 2015 . Formado em 2013 é um grupo atuante com atividades que incluem produção de pesquisas e exposições anuais e que conta com a participação de alunos de diferentes níveis de formação e de diferentes cursos do Centro de Artes. Ainda conta também com a presença de professores colaboradores e artistas da região, alunos de outras unidades da UFPEL, bem como de outras universidades, o que configura o grupo por um viés interdisciplinar, com uma riqueza gerada pela diversidade de experiências de produção, formação e saberes.

Estávamos começando o ano e precisávamos inventar juntos, o que seria desenvolvido pelo grupo como prática efetiva e sendo assim, uma imersão na pesquisa poética, que costumava se configurar com a criação de um livro. Mas, justamente, iniciei com 
essa indagação: Por que escrever um livro? Não tenho dúvidas de que perturbei o grupo com essa pergunta e com esse texto de Julio Cortázar, pois se estávamos reunidos para refletir sobre a produção de Livros de Artista, o fato de eu chegar com a provocação de o porquê escrever um livro, sugerindo até mesmo que havia um excesso de livros no mundo, foi no mínimo paradoxal.

Tínhamos como plano para o ano de 2015 a proposta de Acordar Bibliotecas, com o objetivo de reativá-las a partir de visitas nas escolas vizinhas, propondo um diálogo entre os trabalhos do grupo e os autores que constavam em suas coleçõ̃es. Mas uma dúvida não me deixava seguir adiante, e vinha da atual dificuldade que nós professores universitários temos em trabalhar em disciplinas atingindo uma verdadeira imersão em bibliografias. É preciso admitir isso para tentar encontrar estratégias possíveis. Uma autocrítica se fez necessária. Estávamos prestes a ir acordar bibliotecas, mas a nossa biblioteca funcionava muito mal e aguardava a construção de uma nova que não tinha avançado para além da placa de anúncio da instauração da obra. Um ano já havia passado e acessávamos os livros com muita dificuldade e em horários restritos e por vezes incompatíveis, com as aulas e necessidades de professores e alunos. Esse cenário era mais um fator que me impedia de criticar as formas de uso de outras bibliotecas, pois a consciência de que a nossa ia mal e pouco se fazia para modificar a situação nos provocava para um movimento de crítica interna e até mesmo pessoal. Era necessário um retorno ao pensamento de uma relação pouco lembrada que é a relação leitura e escrita. Fiz uma provocação que serviu como um dispositivo para a reflexão sobre se nós éramos de fato um grupo de leitores, antes mesmo que escritores.

Dessa crítica nasceu um exercício lúdico, que se configurou numa cartografia do grupo, provocando percepções mais alarga- das e até mesmo de autodescobertas. Criamos um projeto chamado JAZIDA. O nome veio por contribuição da aluna Jéssica Porciúncula, através do desafio feito a todos de pensar o que são as bibliotecas. A nossa estava nesta situação, de JAZIDA, ou seja, como fonte potencial de extração de obras, material valioso, mas podia até mesmo piorar ficando apenas no $J A Z$, funcionando mais como uma interioridade inacessível e morta. Perguntávamos: O que é uma biblioteca? As respostas tornaram aquele encontro um dos mais lindos que já tivemos. E as indagações sobre esse espaço não cessaram. Uma biblioteca sem leitores viraria um espaço morto? Vimos que não, que seria no máximo um espaço em repouso. Mas restava a dúvida: como acordar a nossa biblioteca? Como provocar a lembrança de todos de que temos uma biblioteca coletiva e que sua riqueza está justamente na diversidade de obras do campo das Humanidades?

A resposta veio através da criação de um diálogo com a nossa biblioteca pessoal, as que temos em casa, nas nossas prateleiras, na cabeceira da cama, dentro de caixotes empilhados e etc, pois uma biblioteca pode assumir formas diversificadas ao infinito, tal como a Biblioteca de Babel de Jorge Luis Borges (2007). Essa proposição também acessava uma forma particular sobre "A arte e o modo de arrumar os livros", como sugeriu uma vez Georges Perec, pois "na verdade, porém, os livros podem ser reunidos praticamente em qualquer lugar" (PEREC, p.53, 2016). Dessa forma realizamos um inventário que iniciou com a tomada de consciência de que os livros habitam nossa vida, da mesma forma que, ao ler nos propomos habitá-los, e essa proposta tornou-se para o grupo algo revelador também de uma complexidade permeada nos modos de vida.

Criamos um método: Todos me enviariam uma fotografia de parte de sua biblioteca pessoal, num enquadramento que possibilitasse ver os títulos dos livros, e foi aí que começou a acontecer 
algo inusitado. Ao receber as imagens e salvá-las em arquivo passei a ver o todo e a presença de cada um, e essa experiência gerou um jogo involuntário de ligação entre bibliotecas, num desenho invisível, quem sabe, uma aproximação com o conceito de Constelação cunhado por Walter Benjamin, na introdução de sua tese sobre a Origem do Drama no Barroco Alemão. Segundo Benjamin, "As idéias se relacionam com as coisas como as constelações com as estrelas" (BENJAMIN, p.56, 1984). Cada estrela na sua singularidade é parte de um conjunto sobre a forma de uma imagem que a coloca em relação tanto com a imagem quanto com cada uma das estrelas que faz parte do conjunto. Em nossa proposição foi possível ver e imaginar um desenho por via de uma linha de ligação entre o grupo, algo que era invisível antes dessa experiência. Vimos que tínhamos muito mais em comum do que imaginávamos.

Passei a postar as fotos das "estantes" dos componentes do grupo na página que temos em rede social no Facebook, mas sem dizer de quem era cada uma das imagens, como um convite a identificação da pessoa a partir de sua pequena seleção de livros. Uma biblioteca apresenta o seu leitor? Parece que sim. O resultado foi surpreendente, até mesmo aos participantes que se viram através dos livros e que perceberam também essa constelação criada pela repetição de autores em diferentes bibliotecas.

A discussão foi se aprofundando, e a seleção de livros que apareciam na fotografia foi ganhando olhos e pensamentos mais críticos, abdicando do volume excessivo e selecionando o que verdadeiramente é ou foi essencial a cada um do grupo. Esse movimento também nos fez pensar no campo do mercado editorial e a especulação financeira, em que o lucro dificilmente chega aos autores. Pensamos o quanto essa prática de publicação independente, e a autoedição ${ }^{1}$ liberta o autor dessa macroestrutura em que ele muitas vezes desaparece e se distância do público leitor. Essa experiência nos fez ver além da posse material e a pensar no que significa de fato ter um livro e formar uma biblioteca.

Um aluno egresso, Yuri Morroni, escreveu uma carta emocionada ao grupo contando o que essa experiência havia causado nele. Disse que há poucos meses, após a conclusão do curso, tinha retornado para casa e, no entanto, ainda não se sentia parte dela. Foi só ao reabrir as caixas, remexer nos livros para participar da proposição, que finalmente chegou 'em casa'.

Revisitamos, a partir desse relato, o texto de Walter Benjamin chamado Desempacotando minha Biblioteca: um discurso sobre o colecionador. Nesse texto Benjamin, num tom também emocionado, analisa criticamente a formação das coleções de livros e pensa sobre a forma de posse que é estabelecida por um colecionador autêntico. Segundo o autor, o colecionador autêntico é aquele que ama seus livros e vê sua coleção ser formada sempre através do equivalente de vida e sua memória, pois nela "a posse se refere a mais íntima relação que se pode ter com as coisas: não que elas estejam vivas dentro dele; é ele que vive dentro delas" (1987, p. 235). Isso explica, de certa forma, o motivo pelo qual permanecemos com alguns livros, mesmo após sua leitura, e também o porquê retornamos a eles, muitas outras vezes ao longo da vida.

Assim, percebemos não só o tipo de posse que tínhamos, mas o tipo de leitor que exercitávamos em nossas coleções. Dessa análise veio a reflexão de que os livros, mesmo sendo objetos de consumo, não são consumíveis como os demais objetos do mundo, pois são objetos de pensamento, dispositivos que geram duração e exigem uma outra forma de relação e tempo na experiência. Será que ainda é possível compreender as diferenças de tempo que cada coisa nos exige? A dificuldade de ter olhos para ler ao final de um dia, 
após ler/ver vários emails, vídeos, redes sociais, mensagens, televisão, comprova que não estamos sabendo medir ou regular a quantidade e qualidade desse ver/ler.

Nas imagens que recebi do grupo, além dos livros, dos seus autores, da classificação, aparecia o modo de uso, através das marcações, pequenas folhas inseridas por entre os livros criando um testemunho do tempo vivido por esses "lugares", como um diário de leitura. Comentamos sobre os hábitos de leitura, sobre quem lê marcando o texto, sobre quem escreve nas bordas, sobre quem dobra a página e sobre quem, por muito zelo, até mesmo plastifica seus livros. Ao observar o modo de uso, é necessário lembrar de Georges Perec, em $A$ vida modos de usar (2009), em que cada personagem aparece de forma muito rica e sutil, não pela descrição de seu físico ou personalidade, mas pelo levantamento minucioso do seu entorno, seu lar sua pequena coleção de objetos, seu modo de vida. Essa perspectiva dirigida ao Infraordinário, conceito cunhado pelo mesmo autor que enfatiza as pequenas percepções, revela aquilo que na atribulação cotidiana nos escapa. Isso se tornou claro no registro fotográfico das estantes, pois vimos também, além dos livros, pequenos bibelôs, dobraduras, postais, máquinas fotográficas, brinquedos e toda sorte de pequenas "relíquias", um elenco de coisas miúdas convivendo num espaço com escala para livros, inventariadas na vida, destacadas como lembranças junto aos livros, criando outros desdobramentos de sentidos ao conjunto.

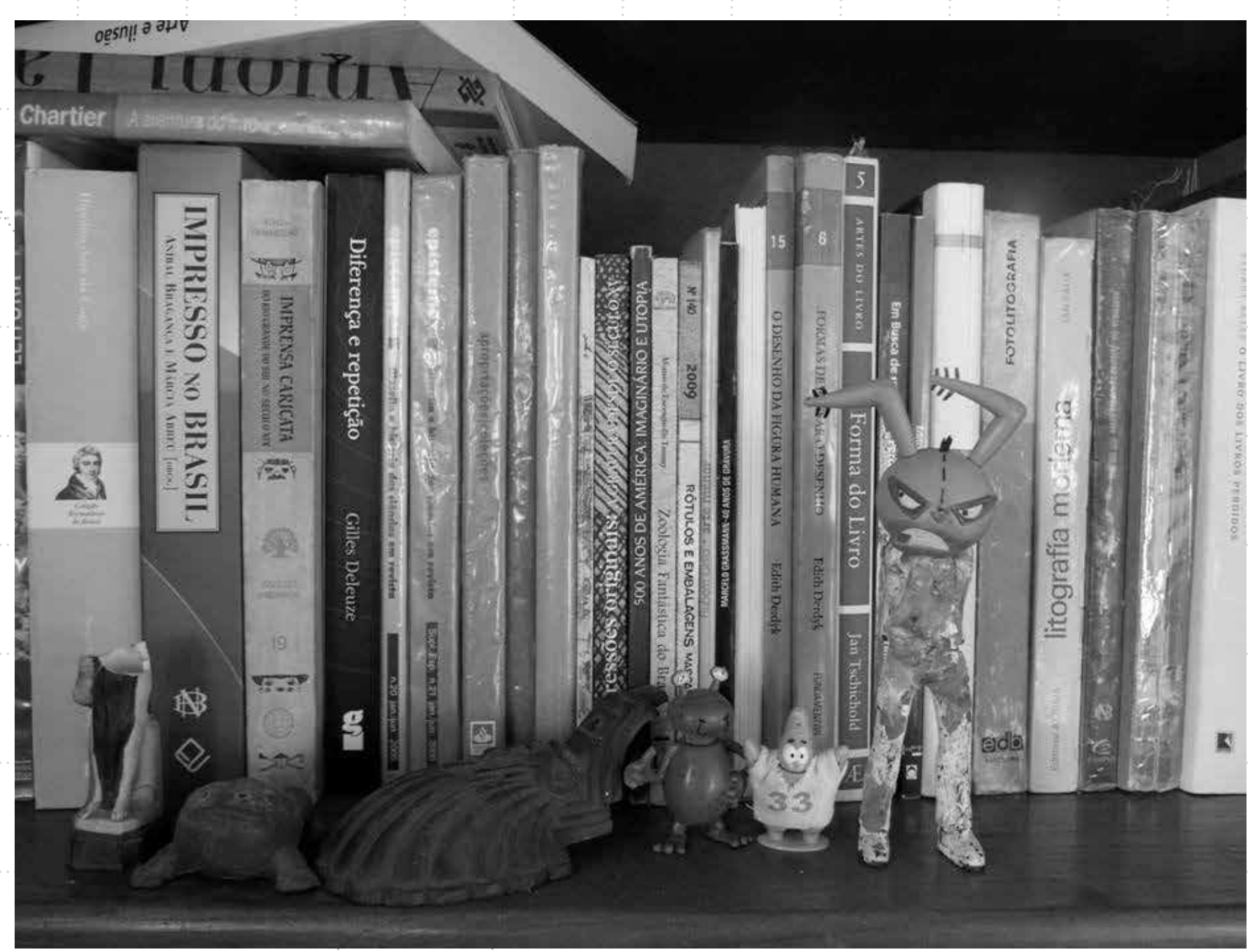

Figura 1. Fotografia de parte da estante de livros de Marcelo Calheiros, abril de 2015

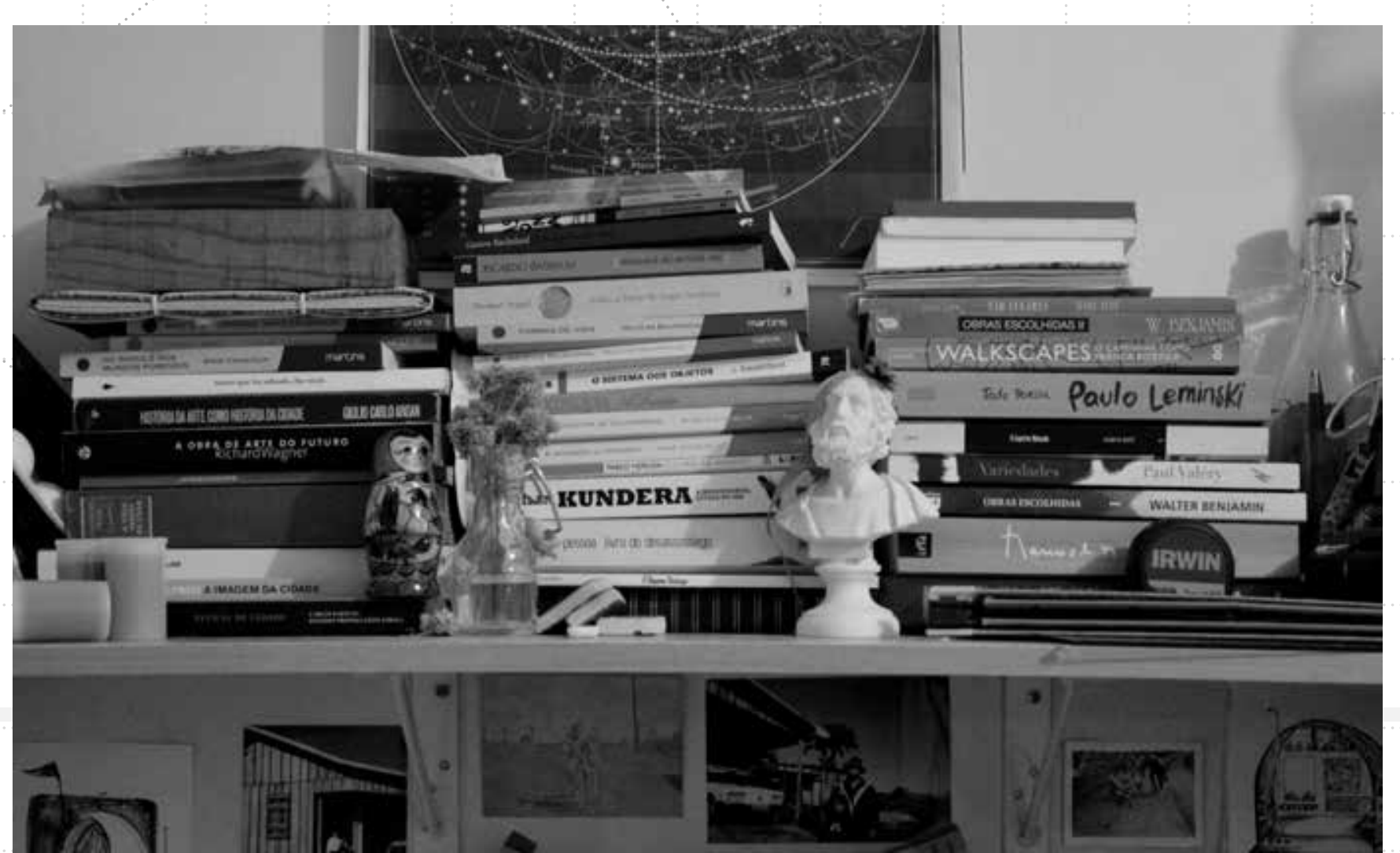

Figura 02. Fotografia de parte da estante de livros de Mariana Corteze, abril de 2015. 


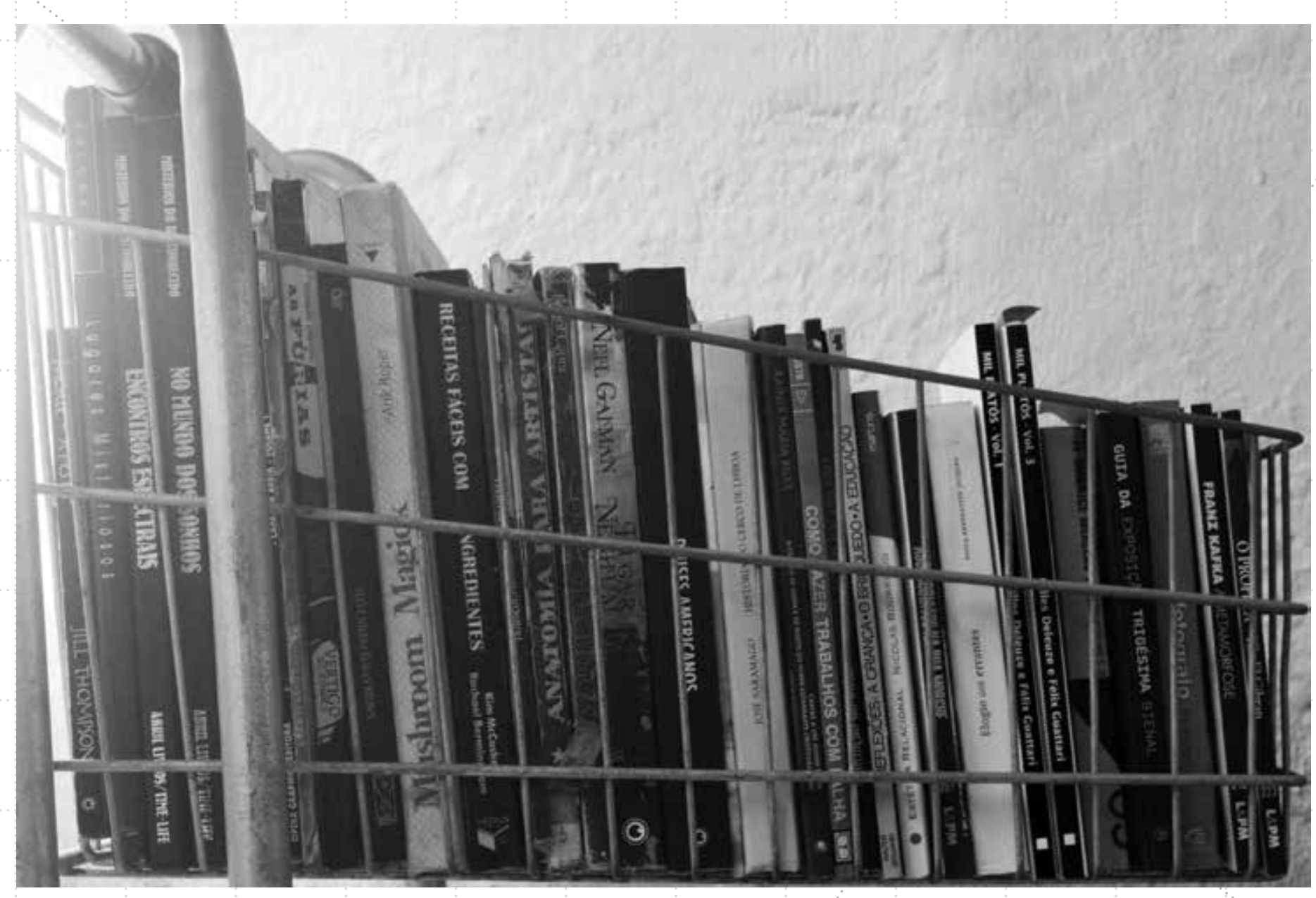

Figura 03. Fotografia de parte da estante de livros de Olides Luan Tavares Bolzon e Isabella Whitaker, abril de 2015.

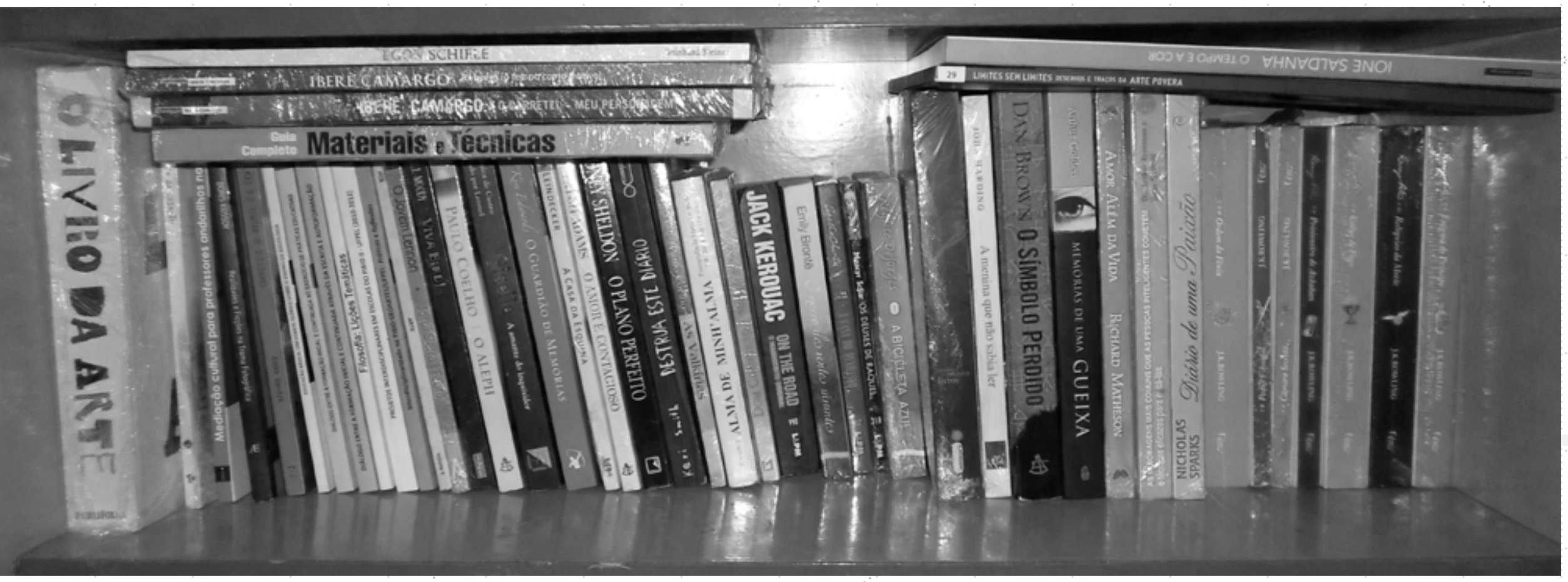

Figura O4. Fotografia de parte da estante de Shayda Cazaubon, abril de 2015.
Algo singular se tornou visível através da forma particular com que cada um organizava seus livros. Conhecemo-nos muito através desse método e passamos a ter maior consciência sobra a biblioteca formada por cada um do grupo e a que nós, involuntariamente, formávamos juntos, conectando-as de uma casa à outra. Alberto Manguel, ao pensar no espaço que criamos ao organizar os livros diz que:

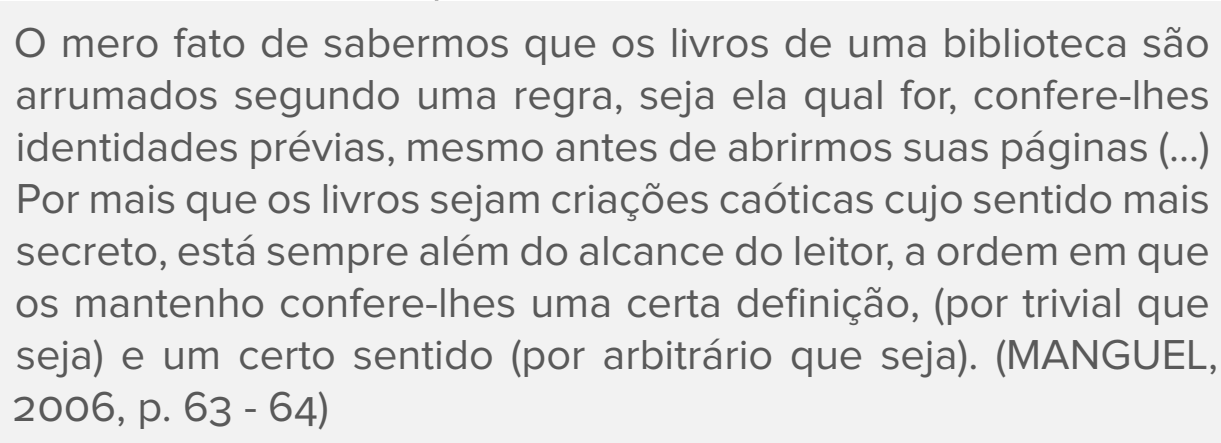

Por mais que o espaço, seus limites e deslimites incidam uma força na organização de bibliotecas, a rotina e os ritmos cotidianos Infraordinários impõe a toda organização um traço da vida, uma ordem ou até a falta dela, fala muito de cada leitor.

Após esse levantamento em forma de imagens e relatos, realizamos uma colagem das mesmas no tapume que protegia a obra da construção da biblioteca, bem em frente onde a atual funcionava com sérios problemas e restrições. A colagem com as imagens realizadas por cada um, levou em conta o formato do recorte fotográfico horizontal, e todas as imagens foram impressas a laser em tamanho A3. Fomos apenas encaixando uma ao lado da outra, criando uma imagem equivalente a uma grande estante repleta de livros, em que a diversidade e os modos de arrumar os livros em cada imagem criava pausas e convidava para observarmos melhor a variedade de autores e títulos. 


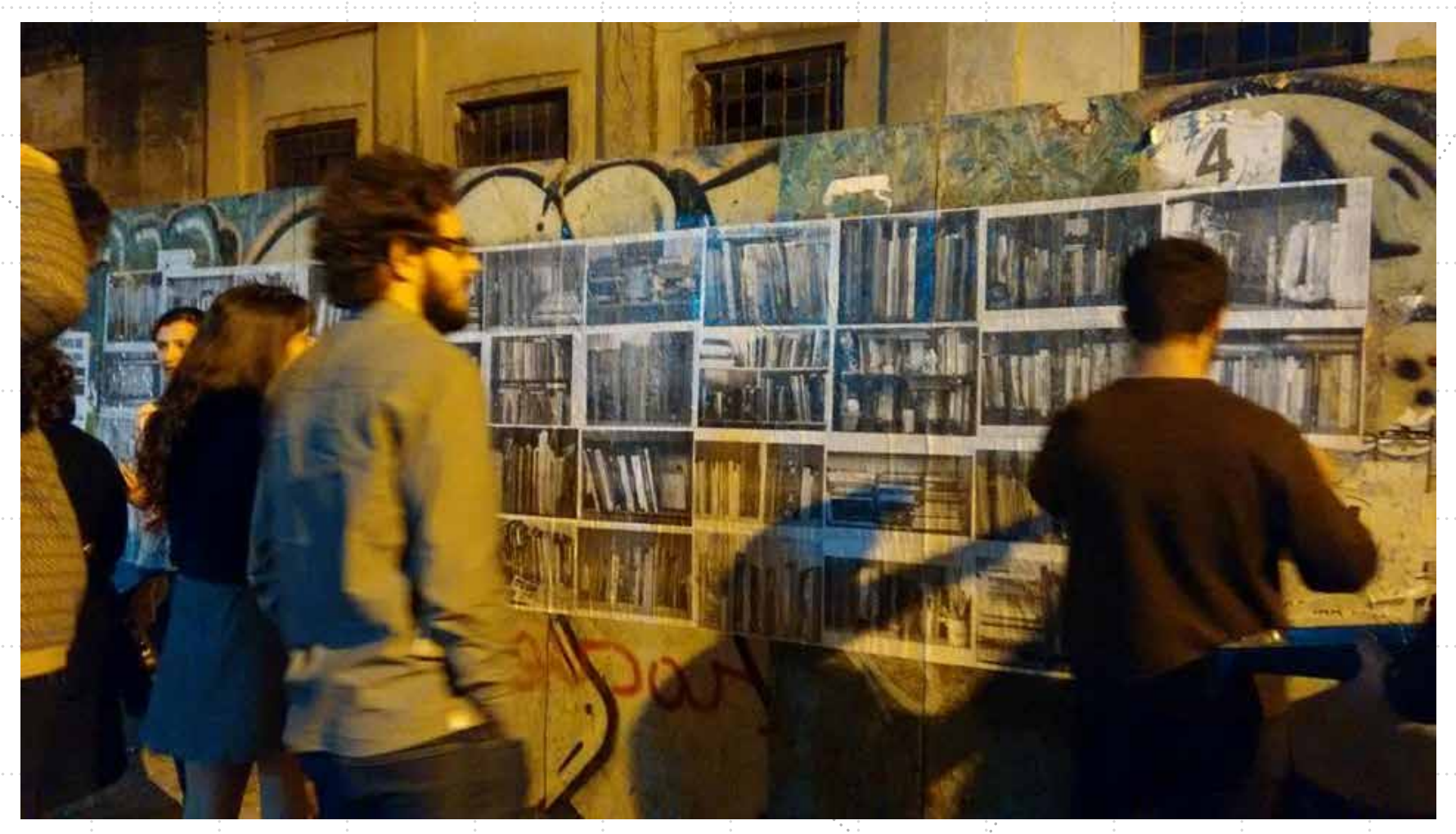

Figura 05. JAZIDA. Registro da ação de colagem com o Grupo Lugares-livros: dimensões poéticas e visuais, Abril de 2015. Fotografia de Rejane Brayer. Local: Tapume da obra da Biblioteca das Ciências Humanas, Ufpel.

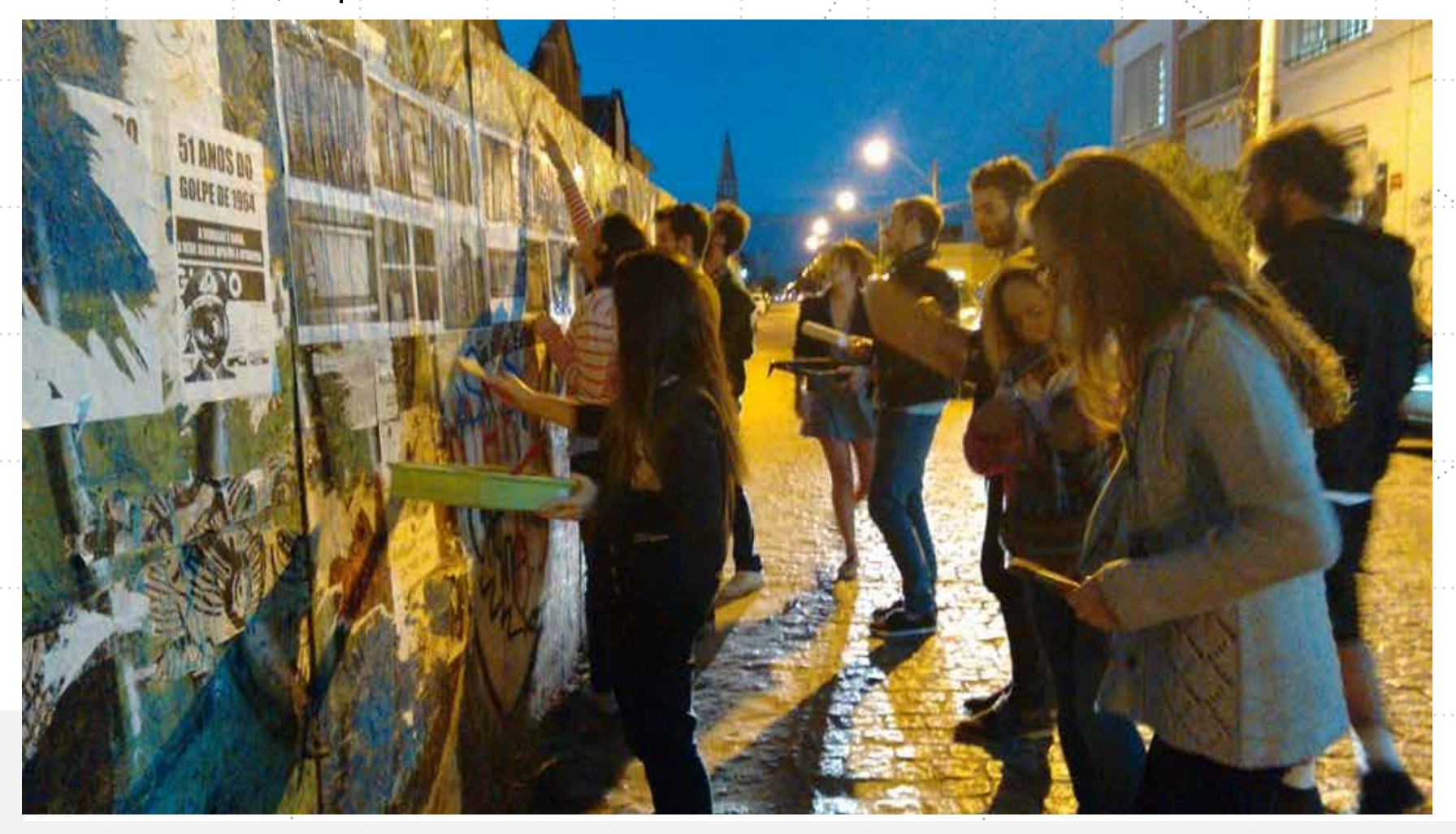

Figura 06. JAZIDA. Registro da ação de colagem com o Grupo Lugares-livros: dimensões poéticas e visuais, em 22 abril de 2015. Fotografia de Carolina Moraes Machese. Local: Tapume da obra da Biblioteca das Ciências Humanas, UFPel.

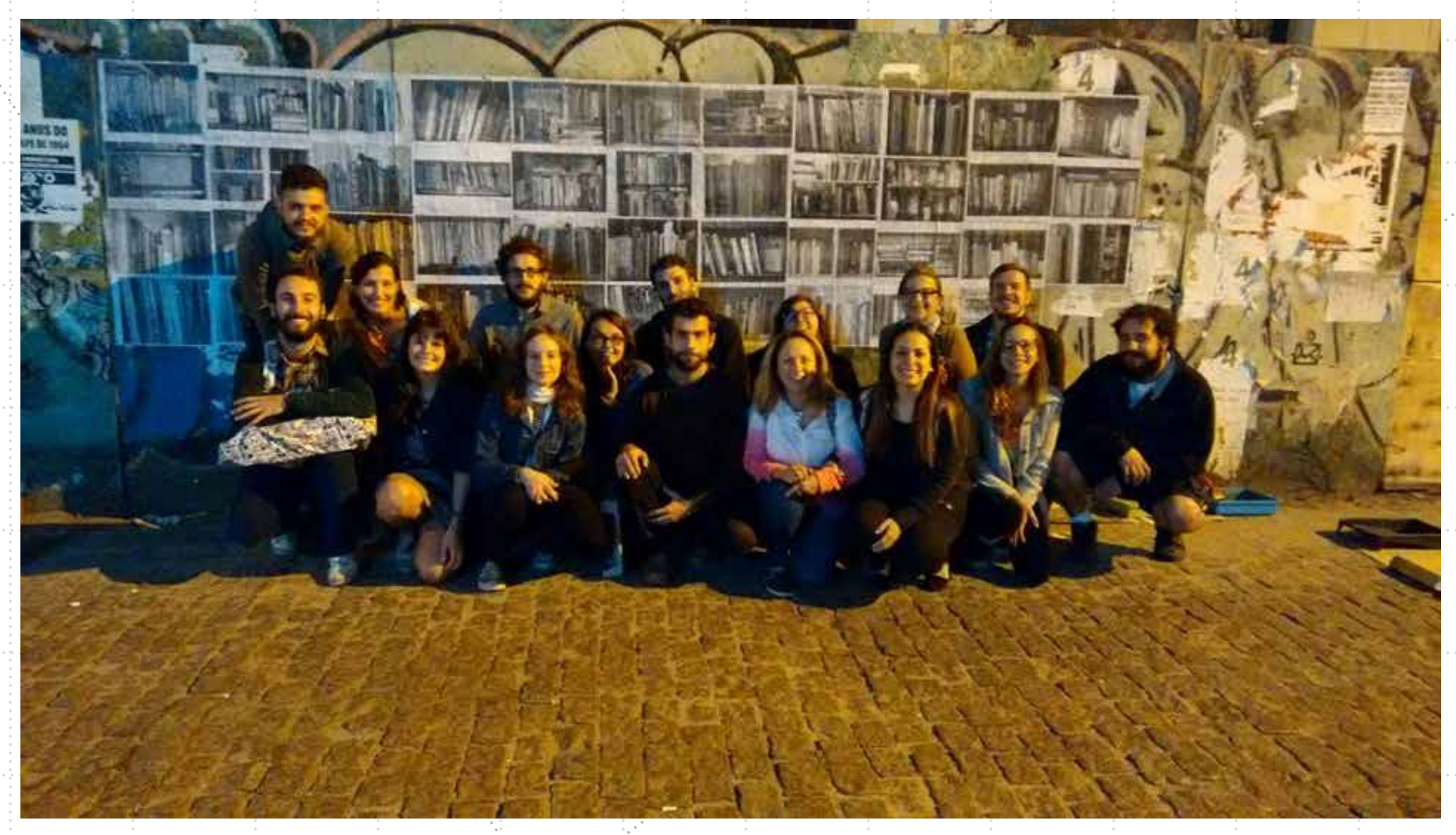

Figura 07. Registro do resultado da Colagem JAZIDA no tapume da obra abandonada da Biblioteca, com parte do grupo presente naquela noite. Fotografia de Rejane Brayer Pereira. Abril de 2015. Local: Tapume da obra da Biblioteca das Ciências Humanas, UFPel.

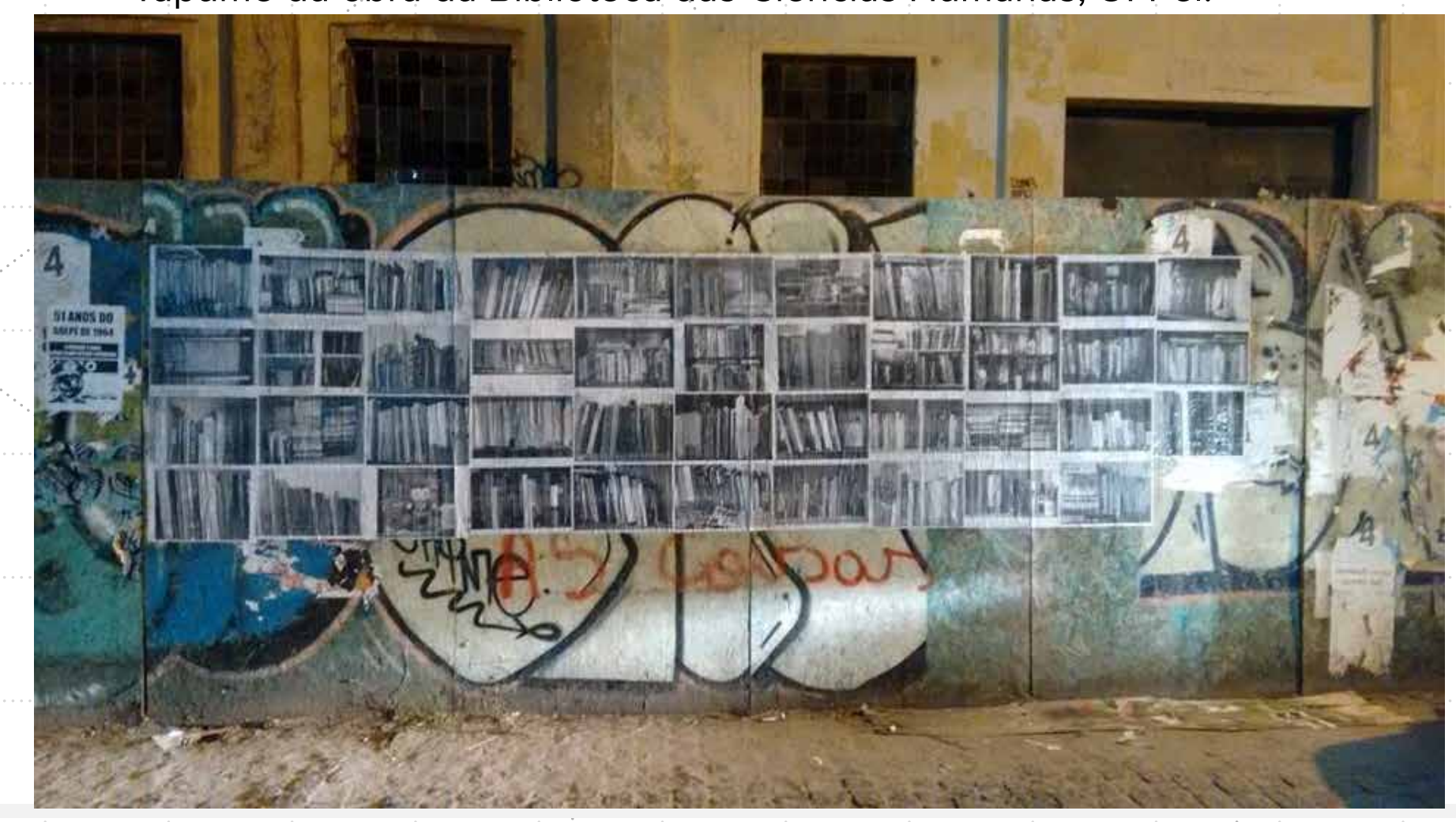

Figura 08. Registro do resultado da Colagem JAZIDA no tapume da obra abandonada da Biblioteca. Fotografia de Rejane Brayer Pereira. Abril de 2015. Local: Tapume da obra da Biblioteca das Ciências Humanas, UFPel. 


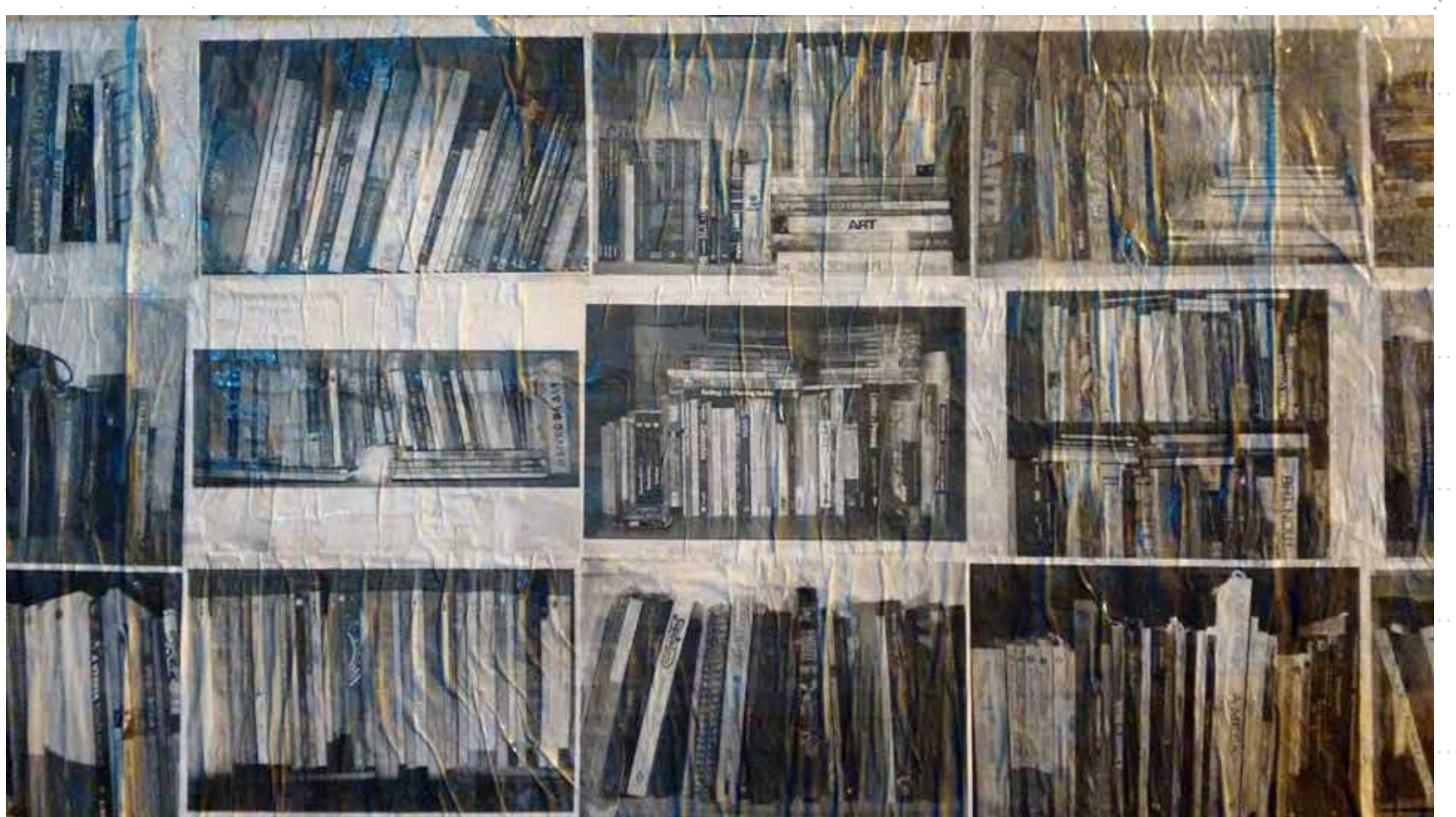

Figura 09. Registro de detalhe da colagem realizada pelo grupo.

Fotografia de Rejane Brayer Pereira. Abril de 2015. Local: Tapume da obra da Biblioteca das Ciências Humanas, UFPel.

A construção da estante JAZIDA por via da colagem se fez, e olhá-la se tornou um exercício de aproximação entre colegas, em obras já lidas e outras que a partir desse momento passaram a ser indicadas, sugeridas entre os membros do grupo. Foi possível perceber uma relação por afinidade de pesquisas e temas, além do que víamos acontecer no nosso método particular de organizar nossas estantes. Foi possível também elencar uma relação de vizinhança entre autores afins. Passamos a imaginar uma lista de livros ainda não lidos e os que gostaríamos de possuir. Não demorou muito para também começarmos a pensar em livros que não existem e que gostaríamos de um dia ler e dessa forma retornamos a provocação que partiu do conto de Julio Cortázar.

A pergunta que todos passaram a fazer, de porquê escrever um livro, foi respondida ao grupo através de Ítalo Calvino no livro Mundo escrito e mundo não escrito: artigos, conferências e entrevis- tas (2015), e com a presença dessa resposta aqui reafirmo o poder e a importância do encontro com essas coleções particulares. Respondendo a uma pergunta semelhante, Calvino lista três motivos: $O$ primeiro fala da insatisfação com a própria escrita e desejo de corrigir ou completar um pensamento que, por ser algo vivo, passa em transformação (2015, p.131). O segundo vem da percepção do efeito que a leitura de certas obras nos causam, nos provocando intensificação e desejo de pensamento, que nos leva à criação de algo novo e, aqui o valor mais uma vez depositado ao papel da leitura e a formação, à reformulação interna que algumas obras nos provocam (2015, p.132). $O$ terceiro motivo, cito aqui diretamente, pois me encontro como artista, professora e pesquisadora em constante aprendizagem, portanto concordo com Ítalo Calvino e acredito ser o motivo fundamental para escrita de um livro ao reafirmar por fim também o valor da pesquisa:

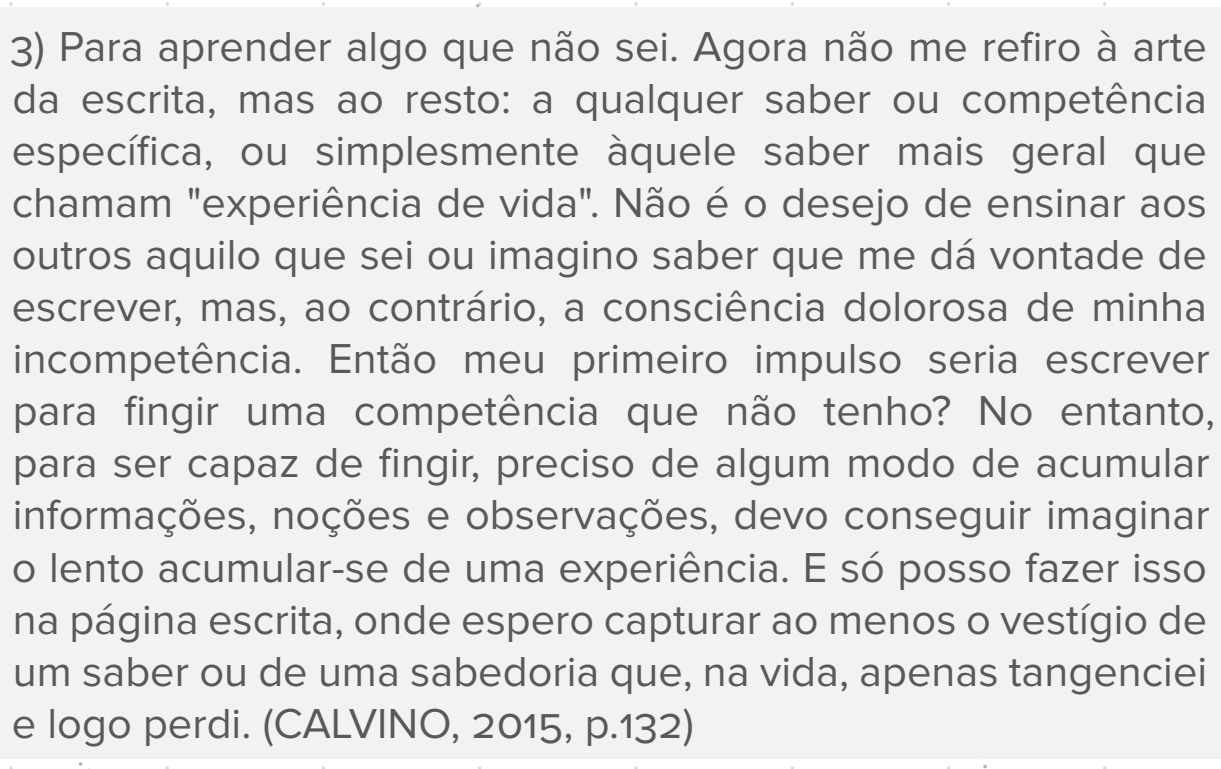

Partindo desses argumentos de Calvino, pensando agora num processo contrário que o conto de Cortázar nos faz imaginar, percebo que: o decrescimento de bibliotecas, a diminuição de leitores, a falta de investimento do setor editorial e o decorrente fechamento de 
editoras no Brasil, e com isso a escassez de novas publicações, têm causado, por conseguinte, a redução de escritores. Aceitar tudo isso seria o mesmo que dizer que já sabemos tudo do mundo, que estamos prontos e que nada mais nos provoca, afeta, encanta, seduz, instiga. Se assim for, estamos mortos, como um corpo que JAZ? Escrita é vida, pensamento em movimento de um corpo sensível. Como enfatiza Ruth Silviano Brandão, "a vida, o que chamamos de vida, realiza na escrita um laço feito de certa resistência, nas várias formas de ler essa palavra, que ao mesmo tempo é ponto de insistência e ponto de opacidade" (2006, p.56). Antes de pensar em escrever um livro é preciso voltar a ver o mundo, aprender por experiência e viver de fato. A página escrita passa a ser um lugar de encontro do que somos e o que procuramos de nós e do mundo. Há algo nessa reposta que já aponta para uma prática utópica de arte e vida. Sim, é importante aproximar esta resistência à potência do ato artístico. E o que pode a arte? A arte produz um corte que propõe reposicionar os sentidos e as formas instituídas, cria assim uma interrupção no presente que faz pensar, faz sentir e pode abrir um espaço crítico e utópico sobre o mundo. Utopia aqui como interdição do presente e não como sonho longínquo (SOUSA, 2004, p. 222). A arte convida a ver/ler de outra forma, propõem a percepção como início de toda a experiência, ela exige de nós outros olhos, corpos livres dos condicionamentos que nos aprisionam por vezes numa única forma de sentir e de viver o mundo e as coisas. Chegamos em algo muito importante que apontei na epígrafe desse texto, na questão da leitura do mundo, ato que, segundo Paulo Freire (1989), precede a leitura de palavras, e no entanto ambas são fundamentais para transformar o mundo a partir de nós mesmos. Então ler, não é só uma condição para o escrever, mas sim para resistir e sustentar também uma condição de liberdade.

As bibliotecas, antes mesmo de se serem um acervo de conhecimento, são o legado humano de nossa insistência no mundo, uma prática utópica que aposta também no leitor do futuro, na maioria das vezes, desconhecido. Dessa forma enfatizo por fim o valor da formação de uma biblioteca, seja pública ou particular. Sabemos que desde sua origem esses espaços foram criados para salvaguardar a produção de conhecimento da humanidade. Pouco se pensa que um longo caminho foi trilhado, e junto a ele toda a sorte de acontecimentos ocorreram, desde a criação, produção, distribuição, mas também investimento de tempo e vida, e por que não lembrar até mesmo da sobrevivência de uma queima obrigatória, ordenada por um tirano em tempos sombrios. As contingências variam de uma época para outra, nada está a salvo, e é por isso que iniciativas de preservação e coleção garantem que um livro chegue finalmente em nossas mãos. Cada encontro e leitura de um livro prolonga uma esperança, pois define uma forma de sobrevivência da obra em cada um de nós. Aqui é impossível não lembrar de Fahrenheit 451, filme de François Truffaut de 1966, baseado no livro de mesmo nome de Ray Bradbury, em 1953. Nessa ficção, bem próxima da nossa realidade atual, a solução para enfrentar tal distopia que proibia a leitura de livros, era resistir se tornando um homem-livro ou seja lendo e assimilando o livro inteiro a ponto de poder contá-lo no futuro para quem o quisesse, ação que retoma não só o valor do leitor, como também do narrador.

Hoje os modos de uso se dinamizaram e estão para além do objetivo da preservação. No entanto, é importante observar que esses espaços, com o avanço da tecnologia e a suposta impressão de que temos acesso a tudo via internet, se tornaram gradativamente menos visitados. E há quem diga que estão mais vazios e silenciosos que o normal ou ideal. Mas será que estão vazios e silenciosos ou somos nós que estamos nos tornando incapazes de ouvir, sentir esses espaços? Acredito que uma biblioteca instaure outros modos de presença 
humana. É preciso voltar a compreender que cada espaço exige de nós um tempo e presenças em específico. É preciso cultivar tempos outros, menos instantâneos e voláteis. Há que se exercitar um tempo biblioteca, mais lento, mais denso e entender que esse tempo faz de nós um outro humano. Também é importante lembrar que, ao procurar por um livro numa biblioteca, sempre encontramos outros mais, que nem imaginávamos antes de nos aventurarmos por entre as estantes. $\mathrm{O}$ acaso e a liberdade desses encontros inusitados podem revelar grandes achados que, na maioria das vezes, escapam às estratégias calculadas em dispositivos de busca online.

\section{REFERÊNCIA BIBLIOGRÁFICA}

BENJAMIN, Walter. Desempacotando minha Biblioteca: um discurso sobre o colecionador. In: Rua de mão única, Obras escolhidas II. São Paulo: Editora Brasiliense, 2000, p 227-235 Origem do drama barroco alemão.Trad. Sérgio Rouanet. São Paulo:
Brasiliense, 1984 .

BRANDÃO, Ruth Silviano. A vida escrita. Rio de Janeiro: 7Letras, 2006, p.56.

BORGES, Jorge Luis. A biblioteca de Babel. In: Ficções. São Paulo: Companhia das Letras, 2007.

CALVINO, Ítalo. Por que vocês escrevem? In: Mundo Escrito e mundo não escrito Artigos, conferências e entrevistas. São Paulo: Companhia das Letras, 2015

CORTÁZAR, Júlio. Fim do mundo do fim. In: História de Cronópios e de Famas. Rio de Janeiro: Editora Record, 2013, p 72-74.

FREIRE, Paulo. A importancia do ato de ler: em três artigos que se completam Paulo Freire. - São Paulo: Autores Associados: Cortez, 1989.

MANGUEL, Alberto. A Biblioteca à noite. São Paulo: Companhia da Letras, 2006. PEREC, Georges. A vida modos de usar: romances. São Paulo: Companhia da Letras, 2009
Notas breves sobre a arte e o modo de arrumar os livros. In: Revista Piaú, 114, ano 10, março de 2016, p 52-54.

SOUSA, Edson. Para não ficar de mãos vazias. In. Corpo, Arte e Clínica. Orgs. Tânia Mara Galli Fonseca e Selda Engelman. Porto Alegre: Editora da UFRGS, 2004 